\title{
NEOCONSTITUCIONALISMO (S) E CONCRETIZAÇÃO DOS DIREITOS SOCIAIS
}

\author{
Renata Bolzan Jauris ${ }^{1}$ \\ Luiz Fernando Bellinetti ${ }^{2}$
}

\section{RESUMO}

O neoconstitucionalismo é um novo paradigma com influxos na teoria jurídica e na prática dos tribunais, enfatizando o papel do Poder Judiciário como concretizador dos direitos fundamentais e sociais, presentes nas constituições contemporâneas. O objetivo da pesquisa é verificar se a teoria neoconstitucionalista é apta a justificar a concretização pelo Poder Judiciário dos direitos sociais diante da alteração sistêmica que produziu no sistema jurídico. A investigação analisará as bases do surgimento da teoria neoconstitucionalista, a lógica desse novo modelo jurídico, e as mudanças que o fenômeno trouxe para a teoria jurídica, especialmente quanto a aplicação dos direitos sociais.

Palavras-chave: Neoconstitucionalismo. Direitos sociais. Princípios. Constituição. Poder Judiciário.

\section{NEOCONSTITUTIONALISM (S) AND SOCIAL RIGHTS CONCRETIZATION}

\begin{abstract}
Neoconstitutionalism is a new paradigm with influences in legal theory and court practice, emphasizing the role of the Judiciary as concretizing of fundamental and social rights, present in contemporary constitutions. The research get to verify if the neoconstitutionalist theory is able to justify the realization by the Judiciary of the social rights before the systemic alteration that produced in the legal system. The research will analyze the foundations of the emergence of neoconstitutionalist theory, the logic of this new legal model, and the changes that the phenomenon has brought to legal theory, especially regarding the application of social rights.
\end{abstract}

Keywords: Neoconstitucionalism. Social rights. Principles. Constitution. Judicial power.

\footnotetext{
${ }^{1}$ Mestranda em Direito pela Universidade Estadual de Londrina (UEL). Juíza de Direito no Tribunal de Justiça do Estado do Paraná.

${ }^{2}$ Doutor em Direito pela Pontifícia Universidade Católica de São Paulo (PUC-SP). Professor da Universidade Estadual de Londrina (UEL). Procurador de Justiça aposentado.
}

Revista de Teorias da Justiça, da Decisão e da Argumentação Jurídica | e-ISSN: 2525-9644 | Salvador | v. 4 | n. 1 | p. 44 - 61 | 


\section{INTRODUÇÃO}

A teoria neoconstitucionalista surge como reflexo do fenômeno evolutivo do Estado Constitucional. A partir do final da Segunda Guerra Mundial, surgiram diversos textos constitucionais que contemplavam em seu bojo direitos fundamentais e suas garantias. A partir de então, o papel do magistrado de mera matriz do texto legal ficou enfraquecido: o juiz passa a assumir um papel criativo do direito.

Seguindo o viés evolutivo, tem-se que o mero reconhecimento dos direitos individuais deixou de satisfazer as necessidades sociais. O Estado Social passou a ser também garantidor da liberdade individual e de condições sociais aptas ao desenvolvimento do ser humano. O direito passa a precisar de uma apreciação valorativa para a adequação à realidade latente e para satisfazer e contemplar os fenômenos sociais que surgiram entre o cidadão e o Estado. Passa então o direito por um processo de redescoberta dos influxos da moral e ética, como em um movimento pendular histórico, entre ideais positivistas e jusnaturalistas.

A despeito das inúmeras questões que são debatidas dentro do neoconstitucionalismo, algumas características básicas são uníssonas no movimento: o padrão principiológico; a ponderação ou balanceamento; supremacia da constituição; a análise partindo, preferencialmente de um caso concreto e o papel de destaque atribuído ao Poder Judiciário. Ao se falar em neoconstitucionalismo, portanto, é comum vincular a aplicação direta da constituição e os princípios a uma forma de realização de justiça no caso concreto.

Partindo da premissa do neoconstitucionalismo como uma realidade jurídica pautada em opções políticas, para saber o papel dessa teoria, se faz necessário saber se constitui de fato uma nova concepção teórica ou se constitui um modelo constitucional que pauta um Estado Constitucional.

Após, diante do reconhecimento na tessitura constitucional dos direitos sociais, e a par do modelo constitucional adotado, analisa-se a possibilidade de concretização direta dos direitos sociais, independentemente da atuação positiva do Poder Legislativo, em contraposição à generalidade com que são formulados os princípios. A generalidade dos princípios impede a concretização dos direitos sociais reconhecidos? Ou, ao revés, amplia a possibilidade de adequação desses direitos aos influxos sociais?

Uma vez que os direitos sociais são geralmente veiculados através de princípios jurídicos, e caracterizam-se historicamente por serem objetivos políticos e meramente 
programáticos, busca-se, por fim, estabelecer o papel da teoria neoconstitucionalista na efetivação de tais direitos. Ressalta-se o papel normativo dos princípios, o processo de ponderação e balanceamento como forma de possibilitar a aplicação direta dos direitos sociais, a partir da criação da consequência jurídica apta e da colmatação dos conceitos jurídicos indeterminados.

Assim, a partir do método dedutivo, a pesquisa divide-se em três tópicos, o primeiro se ocupando da estrutura do conceito de neoconstitucionalismo; o segundo, pertinente à posição do neoconstitucionalismo na teoria do Direito, se como concepção teórica ou um modelo constitucional; e, o terceiro, preocupando-se em indicar os reflexos do neoconstitucionalismo na concretização dos direitos sociais.

\section{SOBRE O NEOCONSTITUCIONALISMO}

Para o devido enquadramento do tema, mister se faz, primeiramente, compreender como se deu o surgimento das ideias que formam o arcabouço social no qual emerge o neoconstitucionalismo.

Luis Roberto Barroso (2006, p. 2-5) considera três marcos fundamentais nos quais estariam contidas as ideias e mudanças de paradigma que alteraram o papel da Constituição na interpretação jurídica em geral: o marco histórico, que na Europa continental foi o constitucionalismo do pós-guerra e no Brasil foi a Constituição de 1988 e o processo de redemocratização que ela ajudou a protagonizar; o marco filosófico, que é o pós-positivismo, assinalado pela superação dos modelos puros por um conjunto difuso e abrangente de ideias agrupadas sob tal rótulo; e o marco teórico, decorrente da alteração do conhecimento convencional quanto à aplicação do direito constitucional, através da expansão da jurisdição constitucional, do reconhecimento de força normativa à Constituição e do desenvolvimento de uma nova dogmática da interpretação constitucional.

A Revolução Francesa é o marco histórico que inicia a idade contemporânea, com o advento do Estado Liberal sobre o Estado Absolutista, e no campo do direito, a ideia da justiça, como único fundamento do direito abre espaço para um direito abstrato criado pela razão humana, o qual poderia ser reduzido a escrito.

Revista de Teorias da Justiça, da Decisão e da Argumentação Jurídica | e-ISSN: 2525-9644 | Salvador | v. 4 | n. 1 | p. 44 - 61 | 
Surge o positivismo, que se apresenta como o jusracionalismo codificado, e que passa a vigorar em vários países europeus. O juiz é visto como mero reprodutor do texto da lei, lei esta que, para esta doutrina, continha todas as soluções. A tarefa do jurista seria mecânica, numa mera repetição automática da solução legislativa. Esta visão é a base do Estado Liberal do século XIX, marcadamente subjetivista, individualista e voluntarista (ASCENSÃO, 2014, p. 19).

As constituições não eram dotadas de força normativa e eram vistas basicamente como programas políticos que, a despeito de serem fonte de inspiração legislativa, não eram arcabouço para a defesa de direitos. (SARMENTO, 2009, p. 116)

A partir da Segunda Guerra Mundial, no entanto, o papel do Juiz, paulatinamente, deixou de ser o de mero repetidor burocrático do texto legal. O Poder Judiciário voltou a adquirir as feições de verdadeiro poder, com a adoção das garantias, autonomia e independência. Acentuaram-se as situações sociais em que as lacunas na lei aparecem, e o papel interpretativo (não mais meramente declaratório) do magistrado como criador do direito toma contornos mais nítidos.

As constituições surgidas no pós-guerra, passaram a se preocupar com o fortalecimento da jurisdição constitucional ante a instituição de mecanismos de proteção dos direitos fundamentais, inclusive quanto às investidas legislativas (SARMENTO, 2009, p. 117). Daniel Sarmento afirma que:

Uma interpretação extensiva e abrangente das normas constitucionais pelo Poder Judiciário deu origem ao fenômeno da constitucionalização da ordem jurídica, que ampliou a influência das constituições sobre todo o ordenamento, levando à adoção de novas leituras de normas e institutos nos mais variados ramos do Direito. (p. 117)

A nova concepção de Estado democrático de direito torna a afirmação positiva do direito não mais suficiente, sendo necessário fazer com que o seu desfrute seja efetivo. É inviável a delimitação do número de direitos, o que torna a separação política entre direito e a moral fator ensejador de ilegitimidade das decisões políticas. A separação entre direito e moral, nesse sentido, tem mais motivações políticas que teóricas e o neoconstitucionalismo passa a ser considerado o porta-voz dessas exigências de fundação, argumentação e justificação do direito, bem como das opções políticas que estão por trás da própria estruturação legislativa. (DUARTE e POZZOLO, 2014, p. 16-20) 
Tradicionalmente a interpretação jurídica desenvolveu-se sobre as premissas relativas ao papel da norma, quanto ao oferecimento, no seu relato abstrato, a solução para os problemas jurídicos e ao papel do magistrado, a quem seria cabível identificar, no ordenamento jurídico, a norma aplicável ao problema a ser resolvido, resolvendo a solução nela contida. As normas percebidas como regras e aplicáveis mediante subsunção são suficientes para o modelo convencional de interpretação (BARROSO, 2006, p.8)

Porém, o modelo convencional de interpretação deixa de ser integralmente satisfatório mediante o avanço do direito constitucional. O relato abstrato do texto normativo nem sempre é suficiente para a solução dos problemas jurídicos e, muitas vezes a resposta constitucionalmente adequada somente pode ser alcançada a luz do caso concreto. O papel do juiz, no mesmo sentido, notoriamente passa a extravasar a função de conhecimento técnico para alcançar o papel de co-participante do processo de criação do Direito, completando o trabalho do legislador as fazer valorações para preenchimento das cláusulas abertas, bem como ao realizar escolhas entre as soluções possíveis (BARROSO, 2006, p. 8).

Nota-se que há um movimento cíclico na história com relação a adoção de teorias que dimensionem as tarefas do juiz no Estado, que variam entre o predomínio da legislação ou da jurisdição. Na sociedade, ante o estado social democrático, há um incremento das atividades do julgador ante a multiplicidade e complexidade crescente da vida social e da expectativa de que a atividade jurisdicional assimile todas essas inovações.

Nesse contexto surge a teoria neoconstitucionalista. Trata-se o neoconstitucionalismo de uma política constitucional que indica não como o direito é, mas como o direito deve ser, e, sustenta a tese que afirma que as suas exigências interpretativas avançadas são estritamente dependentes do modo em que tal doutrina concebe a Constituição. Afirmam Écio Oto Ramos Duarte e Susanna Pozzolo (2014):

Sustento que o modo de interpretar a constituição é estreitamente relacionado com o modo de concebê-la, isto é, a metodologia interpretativa e suas exigências conexas não dependem da configuração, por assim dizer, neutra, objetiva ou verdadeira, mas sim de uma específica reconstrução neoconstitucionalista, em particular, da adoção do modelo prescritivo da Constituição como norma; e a partir daí derivam critérios interpretativos específicos, úteis para caracterizar a mesma doutrina neoconstitucionalista. (p. 78)

A concepção de Constituição neoconstitucionalista determina uma percepção da realidade dos operadores do direito, direcionando a sua práxis e terminando por reconfigurar a 
mesma realidade em que atuam. Nesse passo o neoconstitucionalismo se caracteriza por adotar um modelo prescritivo de Constituição como norma, por considerar que o direito é composto também por princípios, pela a adoção da ponderação ou balanceamento como técnica interpretativa e ainda por dotar a jurisprudência de tarefa de integração e a Teoria do Direito de tarefa pragmática. (DUARTE e POZZOLO, 2014, p. 78/79)

Com o neoconstitucionalismo há uma acentuação da hegemonia axiológica dos princípios que passaram a ser considerados como “pedestal normativo sobre o qual assenta todo o edifício jurídico dos novos sistemas constitucionais”, conforme explica Paulo Bonavides (2003, p. 264).

Humberto Ávila (2009) acentua que não há apenas um conceito de “neoconstitucionalismo” e que, ante a diversidade de autores, concepções, elementos e perspectivas torna-se impossível construir uma teoria unitária do neoconstitucionalismo, e que por esse motivo, inclusive, utiliza-se a expressão no plural para a indicação do movimento. A par da pluralidade das perspectivas em que pode ser estudado o neoconstitucionalismo, Humberto Ávila (2009) elenca algumas mudanças fundamentais. Vejamos:

Mesmo assim, podem ser apontadas algumas supostas mudanças fundamentais -
ocorridas ou meramente desejadas, em maior ou menor intensidade - desse
movimento de teorização e aplicação do Direito Constitucional denominado de
“neoconstitucionalismo”: princípios em vez de regras (ou mais princípios do que
regras); ponderação no lugar de subsunção (ou mais ponderação do que subsunção);
justiça particular em vez de justiça geral (ou mais análise individual e concreta do que
geral e abstrata); Poder Judiciário em vez dos Poderes Legislativo ou Executivo (ou
mais Poder Judiciário e menos Poderes Legislativo e Executivo); Constituição em
substituição à lei (ou maior, ou direta, aplicação da Constituição em vez da lei).

Os valores, para os neoconstitucionalistas, são vistos como expressão de um ideal moral universal e na aplicação do direito, substanciam-se no uso dos princípios, como razoabilidade, proporcionalidade e a técnica de balanceamento. O juiz adquire uma fisionomia positiva e propositiva face a obsolescência do instrumental teórico juspositivista. (DUARTE e POZZOLO, 2014, p. 81)

Écio Oto Ramos Duarte e Susanna Pozzolo (2014, p. 82-84) afirmam que o ordenamento, para os neoconstitucionalistas, se reestrutura em três níveis: regras, princípios e procedimento. A plenitude do ordenamento se alcança pelo segundo nível (princípios) e a crítica ao direito positivo passaria então a evidenciar defeitos internos e objetivos do próprio sistema. 
A justiça se transforma em um dos elementos de validade do direito positivo eis que a validade de uma norma comporta a expressão de um juízo de dever ser que implica razões para justificar ações ou decisões de natureza moral.

Acentua Luis Roberto Barroso (2006, p. 9) que:

O reconhecimento de normatividade aos princípios e sua distinção qualitativa em relação às regras é um dos símbolos do pós-positivismo (v. supra). Princípios não são, como as regras, comandos imediatamente descritivos de condutas específicas, mas sim normas que consagram determinados valores ou indicam fins públicos a serem realizados por diferentes meios.

Nesse contexto, a importância do Poder Judiciário toma maiores proporções, pois passa a ser convocado para resolução de questões polêmicas que envolvam a aplicação de princípios constitucionais colidentes. Tem-se a necessidade de fomento a um sistema harmônico, sem que haja supremacia do Poder Judiciário sobre o Legislativo ou do Poder Legislativo sobre o Poder Judiciário. É necessário o equilíbrio para a sustentação do sistema diante de uma dogmática jurídica que já não se encerra na técnica de subsunção (BRETAS, MATTOS e SCHIER, 2017, p.13-15).

\section{NEOCONSTITUCIONALISMO: CONCEPÇÃO TEÓRICA DO DIREITO OU MODELO CONSTITUCIONAL?}

Miguel Carbonell (2003, p. 9-10) afirma que o termo neoconstitucionalismo, seja no singular ou no plural, pode ser analisado sob duas óticas: como um fenômeno evolutivo com evidentes impactos no que se denomina de paradigma do Estado Constitucional; e como uma determinada teoria do Direito que se tem proposto num passado recente.

Paolo Comanducci (In CARBONELL, 2003, p. 75) explica que o constitucionalismo (ou neoconstitucionalismo), tal qual a divisão do positivismo feita por Bobbio, poderá ser classificado em três vertentes: neoconstitucionalismo teórico, neoconstitucionalismo ideológico e neoconstitucionalismo metodológico.

Para a visão teórica do neoconstitucionalismo, este seria uma forma atualizada da vivência e da aplicação do constitucionalismo enquanto teoria do Direito. Haveria uma reconstrução dos ideais deônticos constitucionais, passando-se a observar como traços

Revista de Teorias da Justiça, da Decisão e da Argumentação Jurídica | e-ISSN: 2525-9644 | Salvador | v. 4 | n. 1 | p. 44 - 61 | 
distintivos a positivação de um catálogo de direitos fundamentais ante a presença, na Constituição, de princípios e regras, e que preenche as lacunas. Aduz Paolo Comanducci (In CARBONELL, 2003, p. 84):

Uma das características distintivas do neoconstitucionalismo teórico (distintivo em relação à teoria tradicional iuspositivista) é, sem dúvida, a tese segundo a qual a interpretação constitucional, como conseqüência do processo de constitucionalização do direito, apresenta hoje, de fato, algumas características peculiares em relação ao interpretação da lei. Mas tais peculiaridades são configuradas de maneira variada conforme um ou outro modelo de Constituição é adotado. Uma vez que me parece que o modelo axiológico da Constituição é adotado como norma, o constitucionalismo não é apresentado como uma teoria do direito, mas sim como uma ideologia, mencionarei, no parágrafo seguinte, sob o título de constitucionalismo ideológico, o correspondente doutrina da interpretação constitucional. ${ }^{3}$

No que tange ao neoconstitucionalismo ideológico, há um afastamento da ideia de constituição como instrumento de limitação do poder estatal, se aproximando da ideia de constituição como instrumento garantidor dos direitos fundamentais. Esse deslocamento ocorre em razão de uma maior confiança depositada nos poderes estatais nos estados democráticos contemporâneos. (COMANDUCCI In CARBONELL, 2003, p. 85).

Obtempere-se que no constitucionalismo ideológico há uma valoração do processo de constitucionalização, ao mesmo tempo que propõe a sua defesa e ampliação e destaca a importância dos instrumentos de tutela dos direitos fundamentais. Paolo Comanducci (In CARBONELL, 2003, p. 86) afirma que promovem essa forma de neoconstitucionalismo Robert Alexy, Ronald Dworkin e Gustavo Zagrebelsky para os quais haveria uma reaproximação entre o Direito e a moral ao passo que haveria uma obrigação moral de obedecer à Constituição e às leis conformes à Constituição. Esse específico sentido de neoconstitucionalismo seria considerado uma variante axiológica moderna do positivismo ideológico do século XIX, que pregava a obrigação moral de obedecer à lei e, ao evidenciar uma especificidade de interpretação constitucional, promove consideráveis alterações no

\footnotetext{
${ }^{3}$ Tradução livre. No original: "Uno de los rasgos distintivos del neoconstitucionalismo teórico (distintivos respecto a la teoría iuspositivista tradicional) es sin duda la tesis según la cual la interpretación constitucional, como consecuencia del proceso de constitucionalización del Derecho, presenta hoy, de hecho, algunas características peculiares respecto a la interpretación de la ley. Pero tales peculiaridades vienen diversamente configuradas según de adopte uno o outro modelo de Constitución. Dado que a mí me parece que, se adopta el modelo axiológico de Constitución como norma, el constitucionalismo no se presenta tanto como una teoría del Derecho sino como una ideologia, mencionaré, em el siguiente parágrafo, bajo el título de constitucionalismo ideológico, la correspondiente doctrina de la interpretación constitucional.”
} 
sistema das regras interpretativas ${ }^{4}$ que passou a considerar o protagonismo dos princípios dentro do ordenamento jurídico.

Por sua vez, o neoconstitucionalismo metodológico sustenta o oposto da visão positivista da possibilidade de diferenciação inicial entre o ser e o dever ser eis que defende a existência de um elo essencial entre Direito e Moral, especialmente quando se trata de situações de direito constitucionalizado, quando os princípios e os direitos fundamentais seriam a ponte entre o Direito e a Moral (COMANDUCCI In CARBONELL, 2003, p. 87). O perigo desta concepção está justamente em aceitar como verdadeira a premissa de que uma norma moral justificaria uma decisão judicial eis que a moral seria equiparada ao normativismo.

Luis Prieto Sanchís (in CARBONELL, 2003, p. 123-158) tal qual Paolo Comanducci, divide o neoconstitucionalismo em três esferas, sendo que duas delas são coincidentes, a acepção teórica e a acepção ideológica. A diferenciação trazida por Luis Prieto Sanchís é quanto a uma terceira acepção, que seria o constitucionalismo como tipo de Estado de Direito. Nesse sentido (In CARBONELL, 2003, p. 123):

O neoconstitucionalismo, o constitucionalismo contemporâneo ou, às vezes também,
o constitucionalismo a secas são expressões ou rubricas de uso cada vez mais
difundidas e aplicadas de maneira um tanto confusa para aludir a diferentes aspectos
de uma cultura jurídica supostamente nova. Eu acho que existem três significados
principais. Em primeiro lugar, o constitucionalismo pode incorporar um certo tipo de
Estado de Direito, designando assim o modelo institucional de uma certa forma de
organização política. Em segundo lugar, o constitucionalismo é também uma teoria

\begin{abstract}
${ }^{4}$ Aqui é válido esclarecer que a partir do neoconstitucionalismo se consagrou a diferenciação do modelo interpretativo e assim, as normas em geral (com especial relevo para as normas constitucionais), seriam divididas em duas espécies, princípios e regras. A diferenciação entre regras e princípios passou a ser o sustentáculo da teoria normativo-material dos direitos fundamentais ao passo que surgem as teorias de Ronald Dworkin e Robert Alexy. Ronald Dworkin (2002, p.39) destaca que tanto as regras quanto os princípios "apontam para decisões particulares acerca da obrigação jurídica em circunstâncias específicas, mas distinguem-se quanto à natureza da orientação que oferecem”. Verificada a validade da regra, a resposta por ela oferecida deve ser aceita, e, sendo inválida, a regra não poderá ser considerada pelo julgador. Já os princípios, prossegue o Ronald Dworkin (2002, p. 41), anunciam "uma razão que conduz o argumento em uma certa direção", e que precisam de uma decisão particular. Por sua vez, Robert Alexy (2008, p. 114/116), diverge com Ronald Dworkin com relação a alguns pontos eis que para ele a diferenciação entre regras e princípios não se dá apenas na graduação, mas também por um critério qualitativo pois as regras contêm determinações do quadro fático e juridicamente possível, encerrando mandamentos definitivos, sendo cumpridas ou não, enquanto os princípios comportam mandados de otimização e por isso tem a função de ordenar a realização de algo maior, dentro das possibilidades fáticas e jurídicas. Para Robert Alexy, portanto, o conflito entre regras ocorre na dimensão da validade, sendo que a colisão entre princípios se dá na órbita de peso (ALEXY, 2008, p.94). Certo é que mesmo com as divergências apontadas ambos apontam para o protagonismo dos princípios como fonte de reconhecimento de valores que deverão integrar e permear todo o ordenamento jurídico.
\end{abstract}


do direito, mais especificamente aquela teoria capaz de explicar as características desse modelo. Finalmente, pelo constitucionalismo também podemos entender a ideologia que justifica ou defende a fórmula política assim designada. ${ }^{5}$

O neoconstitucionalismo como um tipo de Estado de Direito, segundo Luis Prieto Sanchís (2003, p. 125), seria o resultado da convergência de duas concepções que costumavam estar separadas. A primeira é a concepção da Constituição como principal definidora das regras do jogo da função social e política e como garantidora dos mínimos existenciais que permitiriam assegurar a autonomia individual, baseada na ideia de supremacia constitucional. A segunda concepção entende a Constituição como a encarnação de um projeto político, com viés diretivo e com poder de transformação social. (SANCHÍS, In CARBONELL, 2003, p. 125)

O novo constitucionalismo, defende Luis Pietro Sanchís (In CARBONELL, 2003, p. 125) seria decorrente da convergência das tradições constitucionais europeia - com forte conteúdo normativo - e norte-americana - baseada na garantia jurisdicional. Para o autor, os direitos fundamentais representam os limites à democracia, e não pressupostos desta, tal qual no constitucionalismo tradicional.

A despeito das críticas e falhas ${ }^{6}$ apontadas com relação ao movimento constitucionalista o que se observa é que houve um grande avanço na maneira de conceber e tratar o direito e suas fontes, ante ao ressurgimento de uma teoria normativa na qual as normas

\footnotetext{
${ }^{5}$ Tradução livre. No original: "Neoconstitucionalismo, constitucionalismo contemporâneo o, a veces también, constitucionalismo a secas son expressiones o rubricas de uso cada día más difundido y que se aplican de un modo un tanto confuso para aludir a distintos aspectos de una presuntamente nueva cultura jurídica. Creo que son tres las acepciones principales. En primer lugar, el constitucionalismo puede encarnar un cierto tipo de Estado de Derecho, designando por tanto el modelo institucional de una determinada forma de organización política. En segundo término, el constitucionalismo es también una teoría del Derecho, más concretamente aquella teoría apta para explicar las características de dicho modelo. Finalmente, por constitucionalismo cabe entender también la ideología que justifica o defende la fórmula política así designada.”

${ }^{6}$ O próprio Paolo Comanducci no texto aqui citado, "Formas de (Neo) Constitucionalismo: Un análisis metateórico” (In CARBONELL, 2003, p. 87-98) faz conclusões críticas a cada uma das vertentes. Aponta, resumidamente, a compatibilidade teórica entre o neoconstitucionalismo teórico e o positivismo metodológico, ante a troca de modelos de Estado ocorrida, afirmando que “...la teoría del Derecho neoconstitucionalista resulta ser nada más que el positivismo jurídico de nuestros días” (p. 88) e se opõe as alterações propostas por Luigi Ferrajoli e Gustavo Zagrebelsky, as quais trariam uma reconstrução do padrão e das tarefas da teoria do Direito. Quanto ao neoconstitucionalismo ideológico, Paolo Comanducci critica a consequência advinda da adoção da teoria, que seria a diminuição do grau de certeza do Direito derivada da técnica da ponderação dos princípios constitucionais e da interpretação moral da Constituição (p. 91). No que tange ao neoconstitucionalismo metodológico, a crítica de Paolo Comanducci se refere à tese de que qualquer decisão jurídica, especialmente a judicial, se justifica se, em última instância, derive de uma norma moral. Ressalta que acolher este entendimento geraria para o julgador problemas ontológicos e epistemológicos eis que ao juiz caberia escolher a norma que acredita ser moral, o que, - ante as divergências que também existem sobre a definição das normas morais - seria equivalente a deixar completamente nas mãos dos juízes o modo de fundamentar e justificar as suas decisões.
} 
não se reduzem a simples regras eis que se entrelaçam com princípios e valores. Mister se faz destacar ainda a revisão ocorrida da teoria da interpretação, que passou a permitir o trato com normas de estrutura mais aberta e complexa, que exigem mais que simples subsunção para a sua interpretação. Nota-se, portanto, que houve, com o neoconstitucionalismo, um desprendimento da preocupação pura e simples com as estruturas formalistas para se enfocar os conteúdos materiais dos direitos.

A concepção neoconstitucionalista, nota-se, está imiscuída por um forte caráter ideológico. Este caráter ideológico impede a afirmação do neoconstitucionalismo como uma teoria do Direito, eis que ao considerar a constituição como, a um só tempo, norma e metanorma, impossibilita a inclusão de ordenamentos em que a constituição não tenham um caráter verdadeiramente normativo, sem que haja perda da eficácia.

Essas deficiências, como teoria do direito, permitem concluir que o neoconstitucionalismo está mais preocupado em apresentar uma definição de Estado constitucional do direito do que em apresentar um conceito de direito. Assim, é possível afirmar que o neoconstitucionalismo não segue uma linha realmente descritiva, que é um requisito para constituir uma teoria do direito. Por não conseguir separar argumentos ideológicos e políticos de sua análise do direito, ele falha na tarefa de constituir uma teoria do direito que seja capaz de substituir o positivismo jurídico. ${ }^{7}$ (MOLLER, 2008, p. 163)

O constitucionalismo, portanto, como uma forma de definição do Estado Constitucional, apresenta compatibilidade com o positivismo jurídico ao passo que igualmente, pauta a compreensão do direito baseado em um ordenamento com uma Constituição rígida, com controle judicial de constitucionalidade das leis e que atribui força normativa ao texto constitucional programático, com relevo diferenciado quanto as peculiaridades da interpretação constitucional (GUASTINI In CARBONELL, 2003, p. 49-55).

\section{DIREITOS SOCIAIS E NEOCONSTITUCIONALISMO}

\footnotetext{
7 Tradução livre. No original: "Estas deficiencias como teoría del derecho, permiten concluir que el neoconstitucionalismo está más preocupado por presentar una definición de Estado constitucional de derecho, que por presentar un concepto de derecho. Así, es posible afirmar que el neoconstitucionalismo no sigue una línea realmente descriptiva, lo que es requisito para constituir una teoría del derecho. Al no conseguir separar argumentos ideológicos y políticos de su análisis del derecho, falla en la tarea de constituir una teoría del derecho que pueda sustituir al positivismo jurídico.”
}

Revista de Teorias da Justiça, da Decisão e da Argumentação Jurídica | e-ISSN: 2525-9644 | Salvador | v. 4 | n. 1 | p. 44 - 61 | 
André Ramos Tavares (2012, p. 837) conceitua os direitos sociais como aqueles que exigem do Poder Público uma atuação positiva, uma forma atuante de Estado na implementação da igualdade social dos hipossuficientes. São, por esse exato motivo, conhecidos também como direitos a prestação, ou direitos prestacionais.

O que se observa é que os direitos sociais apareceram no cenário jurídico após a assunção dos direitos individuais de liberdade, ao passo que se infere que os direitos sociais surgem justamente para suprir uma lacuna deixada pelos direitos individuais: são direitos fundados na necessidade de intervenção estatal, na solidariedade social, e na necessidade de mitigação das desigualdades sociais.

Em outro giro, o neoconstitucionalismo possibilitou a incorporação ao sistema jurídico de influxos sociais. Isso porque ao se possibilitar a discussão jurídica sobre a necessidade de estabelecer o sentido de conteúdos materiais e valorativos, passou-se a incorporar à prática jurídica, através da interpretação de normas abertas e indeterminadas, os valores sociais. Os valores e princípios terão o sentido atribuído pela prática jurídica, e não aqueles discricionariamente definidos pelo julgador como padrão moral. (MOLLER, 2008, p. 165)

Constitui-se como característica fundamental do neoconstitucionalismo a ênfase aos princípios. Ocorre que os princípios são normas que possuem estrutura diferenciada das regras eis que não obedece a estrutura dependente de um pressuposto fático relacionado a uma consequência jurídica predeterminada ante a presença do nexo causal. Os princípios possuem intensa carga valorativa, protegem bens jurídicos e não fatos jurídicos específicos.

Os princípios formam o arcabouço do Estado Democrático de Direito, ao passo que definem as escolhas políticas da sociedade e refletem na implementação da ordem jurídica. Afirma Sérgio Alves Gomes (2011, p. 222 -223):

Consideradas as distinções entre princípios e regras, percebe-se com lentes da "nova hermenêutica constitucional” que o Estado Democrático de Direito é paradigma estatal estruturado por meio de princípios considerados em sua Constituição como princípios fundamentais. São eles que configuram os fundamentos, valores e objetivos que a sociedade tem em mente ao instituir, pelo poder constituinte, o aludido paradigma estatal.

Na aplicação do ordenamento o operador do direito deverá ter em mira a aplicação da Constituição e, mesmo nas oportunidades em que as decisões podem ser tomadas com base em 
aplicação das regras, deverá ter como vetor os princípios constitucionais elementares (BELLINETTI, 2006, p. 823).

De acordo com Luiz Fernando Bellinetti (2006, p. 824):

Evidentemente, a implementação desses princípios, que devem estar sempre presentes na aplicação de qualquer norma jurídica, deverá ser feita em vista dos fins sociais a que a regra se dirigir e às exigências do bem comum (art. 5. ${ }^{\circ}$ da LICC), de forma a que o operador do direito possa sempre adequar a regra à realidade social vigente no momento. Porém, sempre respeitando os limites impostos pelos princípios constitucionais citados. Isto porque hoje acredito que tais princípios contêm o mais próximo que democraticamente se pode chegar do direito natural.

Os princípios são mandados de otimização eis que ordenam que se realize algo da melhor maneira possível e podem ser cumpridos da melhor forma (ALEXY, 1988, p. 143) e orientam comportamentos. O grau de concreção dos princípios varia conforme o sistema jurídico, a realidade cultural, histórica e em razão das regras com as quais se relaciona.

Para os neoconstitucionalistas, a atuação do intérprete deve incidir sobre a aplicação: o sentido da norma e dos princípios é invariável e constante, o que muda é a relação de força e hierarquia entre eles baseada nas propriedades que emergem do caso concreto (DUARTE e POZZOLO, 2014, p. 111). Diante das circunstâncias próprias do caso concreto, portanto, exigese do intérprete a construção adequada de uma solução e, faltando uma regra que dê suporte à situação jurídica enfrentada, exige-se do intérprete a posição ativa de construção de uma solução adequada de acordo com as circunstâncias e princípios que envolvam.

Ocorre que as regras que encetam direitos sociais possuem como característica serem principiológicas, ao passo que ante o seu descumprimento não há uma sanção diretamente prevista pelo ordenamento. A implementação dos direitos sociais, desta feita, exige a criação de soluções para o caso concreto, que podem, inclusive, passar por um modo gradual de implementação.

Max Möller (2008, p. 484) afirma que os direitos sociais são direitos em forma de princípios uma vez que são fluidos e mudam de acordo com a situação social e as partes envolvidas, não admitindo, desta feita, a submissão a consequências jurídicas pré-determinadas. Conclui:

Entendemos que os direitos de benefícios sociais constituem o método perfeito de aplicação e estudo da doutrina neoconstitucionalista para que, compreendendo as alterações propostas pelo neoconstitucionalismo no cenário jurídico contemporâneo,

Revista de Teorias da Justiça, da Decisão e da Argumentação Jurídica | e-ISSN: 2525-9644 | Salvador | v. 4 | n. 1 | p. 44 - 61 | Jan/Jun. 2018 
seja certamente mais fácil compreender os critérios de aplicabilidade conferidos aos benefícios sociais. nos mais diferentes sistemas jurídicos citados nessa investigação. ${ }^{8}$ (MOLLER, 2008, p. 484)

O neoconstitucionalismo provê de instrumental teórico os defensores da aplicabilidade direta dos direitos sociais eis que possibilita a interpretação dos termos abertos (conceitos jurídicos indeterminados), que antes exigiam a atuação legislativa para a implementação, através da prática social. Permite-se, assim, com a interpretação judicial dos termos abertos, o estabelecimento de debates políticos dentro das estruturas jurídicas.

Os tribunais, frequentemente, têm sido levados a se manifestar com relação a omissões legislativas e à implementação de políticas públicas. Daniel Sarmento (2009, p. 128) afirma que há um entrelaçamento entre a jurisdição constitucional, a argumentação jurídica e a Filosofia Política, promovendo-se uma abertura de espaço para a adoção de uma posição substancialista que se identifica com o neoconstitucionalismo ao passo que a crença numa legitimidade do ativismo judicial em favor dos valores constitucionais tem gradativamente aumentado.

Max Möller (2008, p. 487) afirma que a adoção da aplicação direta pelos tribunais, mais que uma postura radicada na Teoria do Direito, não é uma decisão meramente jurídica. A adoção do neoconstitucionalismo gera uma postura diferenciada pelo intérprete em sua relação com a atividade judicial e as possibilidades normativas dos princípios. Esta postura diferenciada, por sua vez, pauta-se e gera uma posição política por parte dos julgadores.

Nesse sentido, arremata Max Möller (2008, p. 490):

a lei sofre forte influência de um movimento ideológico conhecido como neoconstitucionalismo. Este movimento, sob vários argumentos discutidos aqui, propõe, em suma, a necessidade de uma mudança na atitude dos intérpretes, adotando uma postura mais ativa. Essa posição, por argumentos da teoria constitucional, afetará a forma de avaliação do juiz em questões políticas. Se visualizarmos as possibilidades oferecidas aos sistemas a partir daquela posição constitucionalista, pode-se verificar que grande parte da discussão jurídica sobre a aplicabilidade direta dos direitos de benefícios sociais será o mero resultado de uma ordem, por meio de seu Tribunal Constitucional, de optar ou não. para a assunção dessa tutela direta, com todos os

\footnotetext{
8 Tradução livre. No original: "Entendemos que los derechos sociales prestacionales constituyen el perfecto método de aplicación y estudio de la doctrina neoconstitucionalista de manera que, comprendiendo las alteraciones propuestas por el neoconstitucionalismo en el escenario jurídico contemporáneo, seguramente resulta más fácil comprender los criterios de aplicabilidad conferidos a los derechos sociales prestacionales en los más distintos ordenamientos jurídicos citados en ésa investigación.”
} 
problemas e complicações que isso acarreta. Ambas as opções são válidas, viáveis, legais, lógicas e respeitáveis. ${ }^{9}$

No Brasil, observa-se que o Supremo Tribunal Federal tem admitido o controle da aplicação dos direitos sociais diretamente pelo Poder Judiciário, como ocorre com a jurisprudência já estabelecida quanto ao direito à saúde ${ }^{10}$ e à educação ${ }^{11}$.

Com relação a influência da doutrina neoconstitucionalista na jurisprudência do Supremo Tribunal Federal, Daniel Sarmento (2009, p. 129) afirma que os princípios abertos têm sido a cada dia mais utilizados julgamentos proferidos pela Corte, que frequentemente recorre à ponderação de interesses, ao princípio da proporcionalidade, bem como a referências filosóficas na fundamentação de decisões. Daniel Sarmento (2009, p. 130) acrescenta que “São exemplos eloquentes a alteração da posição da Corte em relação aos direitos sociais, antes tratados como "normas programáticas”, e hoje submetidos a uma intensa proteção social...”.

Assim, diante do aqui exposto, o que se observa é que o neoconstitucionalismo é, sobretudo uma nova forma de conceber o Direito e o Estado, e tem sido utilizado como um modelo constitucional que proporciona e melhor justifica a atribuição de eficácia normativa direta aos direitos sociais.

\section{CONCLUSÃO}

O Constitucionalismo emergente após a Segunda Guerra Mundial caracteriza-se pela adoção de um modelo constitucional voltado para a proteção aos direitos fundamentais. A partir disso, surge a reformulação do papel do Poder Judiciário que abandona a função do juiz de mero reprodutor de textos legais para assumir uma postura ativa e interpretativa e constitucionalização de todo o ordenamento jurídico.

\footnotetext{
9 Tradução livre. No original: ...el derecho sufre una fuerte influencia de un movimiento ideológico conocido como neoconstitucionalismo. Ese movimiento, bajo varios argumentos aquí tratados, propone, en resumen, la necesidad de un cambio de actitud de los intérpretes adoptando una postura más activa. Esa postura, por argumentos propios de la teoría constitucional, va a repercutir en el ingreso del juzgador en cuestiones políticas. Si visualizamos las posibilidades que se ofrecen a los sistemas desde esa postura constitucionalista, se puede comprobar que mucho de la discusión jurídica sobre aplicabilidad directa de los derechos sociales prestacionales será el mero resultado de un ordenamiento, a través de su Tribunal Constitucional, optar o no por la asunción de esa tutela directa, con todos los problemas y complicaciones que acarrea. Ambas opciones son válidas, viables, jurídicas, lógicas y respetables.

10 Agravo de Instrumento no Recurso Extraordinário n. 271.286/ RS, DJU 24.11.2000.

11 Agravo de Instrumento no Recurso Extraordinário n. 410.715-5, julgado em 22.11.2005.
}

Revista de Teorias da Justiça, da Decisão e da Argumentação Jurídica | e-ISSN: 2525-9644 | Salvador | v. 4 | n. 1 | p. 44 - 61 | 
A Constituição funciona então como documento com força normativa vinculante e não mais programática, albergando as escolhas políticas do Estado Democrático de Direito, no qual definida. A Constituição e sua forma de interpretação e integração são os reflexos das escolhas políticas e jurídicas, ao mesmo tempo que funcionam como legitimadoras destas escolhas.

O neoconstitucionalismo representa a política constitucional que reflete o incremento das exigências interpretativas, com base em princípios, valores e ponderação ou balanceamento como técnica interpretativa. A aplicação do direito constitucional, com o advento do movimento constitucionalista, baseia-se na prevalência dos princípios, na preponderância da ponderação sobre a mera subsunção; a construção de soluções para e mediante casos concretos e forte destaque do papel dos Juízes.

A definição e alocação do neoconstitucionalismo dentro da Ciência Jurídica, no entanto, não se mostra uma tarefa simples. Não se pode negar, no entanto, o caráter de fenômeno evolutivo, com fortes impactos no paradigma do Estado Constitucional. O neoconstitucionalismo reconstruiu os ideais valorativos da ordem normativa constitucional, ante a positivação dos direitos fundamentais e de princípios, ao passo que há uma reaproximação entre o Direito e a Moral.

O constitucionalismo, como um tipo de Estado de Direito, parte da função constitucional de definidor das diretrizes políticas e sociais e de garantidor do mínimo existencial, ante a supremacia constitucional. A Constituição assume ainda a projeção das aspirações políticas, estabelecendo diretrizes e com o poder de transformação social, eis que os conteúdos materiais dos direitos assumem papel de destaque.

Por outro lado, o neoconstitucionalismo como uma forma de definição do Estado Constitucional, apresenta compatibilidade com a teoria do Direito positivista, uma vez que não nega a importância das regras e nem desprovê o ordenamento de controle judicial de constitucionalidade, mas sim, atribui força normativa ao texto constitucional, antes programático e dependente da atividade legislativa.

Assim, o neoconstitucionalismo caracteriza-se pela ênfase aos princípios e permite a incorporação ao sistema jurídico dos influxos sociais, ante a possibilidade de prover o sentido de conteúdos materiais e valorativos presentes nos princípios. Através da interpretação de normas abertas e indeterminadas os valores sociais são incorporados à prática jurídica.

Por sua vez, as normas que traduzem os direitos sociais, são, estruturalmente, princípios e não trazem em seu âmago a situação fática delineada e a consequência jurídica 
correspondente. Exigem, portanto, a criação de soluções adequadas e específicas para o caso concreto.

Nesse quadro, tem-se que o neoconstitucionalismo é o instrumental teórico que dá aptidão à aplicabilidade imediata dos direitos sociais. A adoção ou não do neoconstitucionalismo, no entanto, corresponde a uma opção que pauta-se em aportes não apenas jurídicos, mas também políticos, e dimensiona a postura diferenciada e mais ativa dos julgadores.

\section{REFERÊNCIAS BIBLIOGRÁFICAS}

ALEXY, Robert. Sistema jurídico, princípios jurídicos e y razón práctica. Revista Doxa, n. 5, 1988.

Teoria dos direitos fundamentais. - São Paulo: Malheiros Editores, 2008.

ASCENSÃO, José Oliveira. Um direito de cláusulas gerais? Sentido e limites. In: Revista Judiciária do Paraná. Associação dos Magistrados do Paraná - Ano IX, n. 7. Editora Bonijuris: Curitiba, maio de 2014.

ÁVILA, Humberto. "Neoconstitucionalismo": entre a "ciência do Direito" e o "direito da ciência”. Revista Eletrônica de Direito do Estado (REDE), Salvador, Instituto Brasileiro de Direito Público, $\mathrm{n}^{\circ}$ 17, janeiro/fevereiro/março, 2009. Disponível na Internet: $<\underline{\text { http://www.direitodoestado.com.br/rede.asp> }}$. Acesso em: 18 de janeiro de 2013.

BARROSO. Luis Roberto. Neoconstitucionalismo e constitucionalização do direito. In Quaestio Iuris. Vol. 02, $\mathrm{n}^{\mathrm{o}}$ 01, Rio de Janeiro, 2006, p. 1-48. Disponível na internet: $<$ http://www.e-publicacoes.uerj.br/index.php/quaestioiuris/article/view/11641/9106>. Acesso em: 08 de abril de 2018.

BELLINETTI, Luiz Fernando. Direito e Processo. In Processo e Constituição. São Paulo. Ed. RT, 2006, p. 816-826.

BRETAS, Carla Panza. MATTOS, Kennedy Josué Greca. SCHIER, Paulo Ricardo. A teoria do direito e da Constituição no contexto do neoconstitucionalismo pós-positivista: análise da racionalidade. In SCHIER, Paulo Ricardo (coord.). Estado Constitucional e direitos fundamentais. Rio de Janeiro: Lumen Juris, 2017, p. 9-27.

Revista de Teorias da Justiça, da Decisão e da Argumentação Jurídica | e-ISSN: 2525-9644 | Salvador | v. 4 | n. 1 | p. 44 - 61 | 
BONAVIDES, Paulo. Curso de Direito Constitucional. 13ª ed. São Paulo: Malheiros, 2003.

COMANDUCCI, Paolo. Formas de (Neo) Constitucionalismo: Un análisis metateórico. In CARBONELL, Miguel (org.). Neoconstitucionalismo (s). Madrid: Trotta, 2003.

DUARTE, Écio Oto Ramos. POZZOLO, Susanna. Positivismo Jurídico. As faces da Teoria do Direito em tempos de interpretação moral da constituição. $2^{\mathrm{a}}$ ed. São Paulo: Landy, 2010.

DWORKIN, Ronald. Levando os direitos a sério. - São Paulo: Martins Fontes, 2002.

GOMES, Sérgio Alves. Hermenêutica Constitucional: um contributo à construção do Estado Democrático de Direito. $1^{\text {a }}$ ed. (2008), $3^{\text {a }}$ reimpr. Curitiba: Juruá, 2011.

GUASTINI, Riccardo. La “constitucionalización” del ordenamento jurídico: el caso italiano. In CARBONELL, Miguel (org.). Neoconstitucionalismo (s). Madrid: Trotta, 2003.

MOLLER, Max. La aplicabilidade de los derechos sociales prestacionales em los sistemas jurídicos contemporáneos. Tesis Doctoral. Burgos: Universidad de Burgos, 2008.

SANCHÍS, Luis Prieto. Neoconstitucionalismo y Ponderación Judicial. In: CARBONELL, Miguel (org.). Neoconstitucionalismo (s). Madrid: Trotta, 2003.

SARMENTO, Daniel. O Neoconstitucionalismo no Brasil: Riscos e possibilidades. In: SARMENTO, Daniel. Filosofia e Teoria Constitucional Contemporânea. Rio de Janeiro: Lumen Juris, 2009.

TAVARES, André Ramos. Curso de Direito Constitucional. 10ª ed. Rev. E atual. - São Paulo: Saraiva, 2012.

Revista de Teorias da Justiça, da Decisão e da Argumentação Jurídica | e-ISSN: 2525-9644 | Salvador | v. 4 | n. 1 | p. 44 - 61 | Jan/Jun. 2018 